\title{
Dynamic Modeling and Control of a Single-Phase Grid- Connected photovoltaic System
}

\author{
A. Zare and M. T. Iqbal
}

\begin{abstract}
Designing control strategies to connect a photovoltaic (PV) system to the grid has been significantly challenging. This paper focuses on developing a controller for a single-phase PV system connected to the grid and its implementation to modify the power factor in the distribution power system. To design a grid-connected PV system, its components are modeled, such as PV panels, Maximum Power Point tracking (MPPT) algorithm, the grid interface inverter with the appropriate filter, and the DC link capacitor. SIMULINK / MATLAB is used for simulation in this study. The proposed control strategy is designed to track the maximum power point of The $P V$ panels and control the $P V$ active and reactive output power. In this paper, the presented reactive power control provides the $P V$ system with power factor correction (PFC) capability. The proposed technique for checking controller validity is tested, and the results prove that the proposed controller is good and provides the required performance.
\end{abstract}

Index Terms - MPPT; solar energy; PV; PFC; Simulink; modeling; renewable energy.

\section{INTRODUCTION}

Fossil fuels significantly satisfy global energy demand and are likely to keep their future impact. However, fossil fuel sources are limited, so that they cannot meet worldwide energy demands. Therefore, renewable energy sources (RES) importance has been evident. Solar energy systems are one of the most widely utilized sources of RESs [1]. Another advantage of using solar energy is that in contrast with fossil fuel power plants, the sun's energy has no adverse impact on the environment [2], [3]. Hence, researchers pay more attention to this issue. PV systems are widely utilized in various fields, such as grid-connected systems, heating and irrigation applications, and space transportation. Energy production takes many advantages of PV panels [4]. However, performance depends on meteorological conditions such as temperature, solar radiation level, shading, and dust.

Therefore, transferring the maximum power from PV panels is a significant concern. By employing a power point tracking technique, the highest available amount of energy is captured. The most common MPPT techniques are Perturb \& Observe and Incremental Conductance algorithms because they are simple and highly effective [5]. Since these techniques are autonomous of photovoltaic characteristics while tracking the Maximum Power Point (MPP), they are the most advantageous techniques.

As a result, MPPs accomplishments attract more attention, which are essential circumstances for inverter tied to the grid controlling active $(\mathrm{P})$ and reactive $(\mathrm{Q})$ power [6]. Several researchers have investigated grid-connected inverters. While in some of their research, inverters are suggested to control only the injected $\mathrm{P}$ to the grid. Some researchers also investigate multi-functional grid-connected inverters [7,8]. The inverters function to Provide the available PMAX and QMAX, provide $\mathrm{Q}$ concerning the voltage, and determine the power factor and reactive power mode [9]. As increasing attention turns to RES, the inverters tied to the grid have received significant attention [10].

In this paper, a control scheme for a single-phase PV system connected to the grid is presented to modify the power factor to prevent grid voltage instability at the Point of Common Coupling (PCC). The incremental conductance method, as an MPPT algorithm, assures the maximum power transfer to the grid. In the proposed system, a singlephase inverter controls the current injected into the grid. The controller adjusts the current without surpassing line restrictions. Moreover, the inverter injects $\mathrm{Q}$ required by the grid. The $\mathrm{Q}$ demanded by the grid is supported by the PV even when solar irradiation is zero. The control algorithm is simulated, and the evaluation of the results has been done. The suggested control algorithm presented in the study combines the MPPT, P control technique, and power factor controller. Therefore, an effective controller is obtained to directly control the $\mathrm{P}$ and $\mathrm{Q}$ of the grid-tied PV system.

\section{GRID-CONNECTED ROOFTOP PV SYSTEM}

The schematic diagram of a PV system tied to the grid is presented in Fig. 1. The PV module and the DC-link capacitor are interfaced with the grid via inverter with the proper filter and controllers at PCC.

$I_{i n v}$ and $I_{L}$ express the inverter output and the load current, respectively. $V_{s}$ is the source voltage at PCC. The inverter DC link voltage is represented with $V_{D C}$ given by the PV solar system. $L_{f}$ and $C_{D C}$ refer to the $L$ filter parameter and the DC link capacitor, respectively.

The control strategy suggested in this paper utilizes grid parameters to generate the inverter's control pulses. 


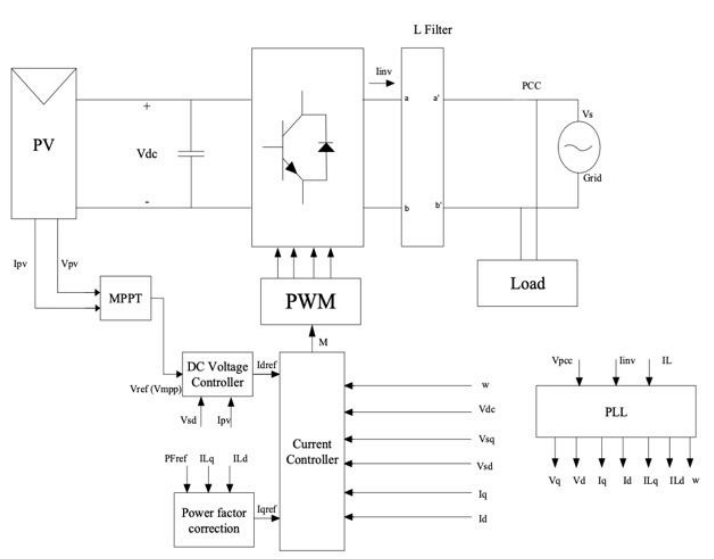

Fig. 1. PV Grid-Tied system block diagram.

\section{A. PV Source Model}

To analyze the grid-connected PV system, modeling the PV module using data from the manufacturer datasheet is essential. Fig. 2 demonstrates the equivalent circuit of a practical PV cell.

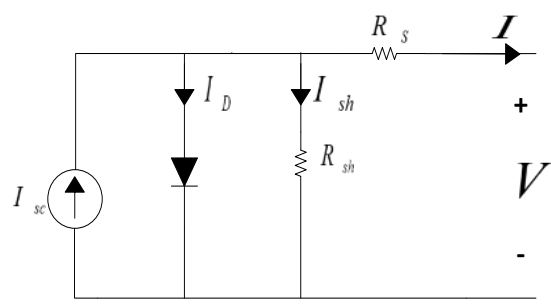

Fig. 2. PV cell equivalent circuit.

It includes a diode non-parallel with a current source, a parallel and a series resistor. The basic equation for describing the I-V properties of a solar cell can be obtained using Kirchhoff's current law on the equivalent circuit of a PV cell.

$$
\mathrm{I}=I_{s c}-I_{d}-I_{s h}
$$

$I, I_{s c}, I_{d}$, and $\mathrm{I}_{\mathrm{sh}}$ represent output cell current, short circuit current, the diode current, and the parallel branch current, respectively.

$$
\begin{aligned}
& I_{d}=I_{o}\left[\exp \left(\frac{V-I R_{S r}}{\mathrm{n} k T_{c} / q}\right)-1\right] \\
& I_{s h}=\left(V+I R_{s r}\right) / R_{s h}
\end{aligned}
$$

After Substituting the equations (2) and (3) in (1), output cell current has the following equation [15].

$$
\begin{array}{r}
I=I_{s h}-I_{o}\left[\exp \left(\frac{V-I R_{s r}}{\mathrm{n} k T_{c} / q}\right)-1\right]-\left(\frac{V+I R_{s r}}{R_{S h}}\right) \\
I_{s c}=I_{s c R} \frac{G}{G_{R}}\left[1+\alpha_{T}\left(T_{c}-T_{c R}\right)\right]
\end{array}
$$

$G$ refers to solar radiation in the solar cell plate and $T_{c}$ represents cell temperature. $I_{o}$ in equation (4) depends on the temperature of the cell. It is called the dark current.

$$
I_{o}=I_{o R}\left(\frac{T_{c}^{3}}{T_{c R}^{3}}\right) \exp \left[\left(\frac{1}{T_{c R}}\right)-\frac{1}{T_{c}}\right] \frac{q e_{g}}{n k}
$$

$\mathrm{I}_{\mathrm{scR}}$ refers to the short-circuit current solar radiation reference $G_{R}$ and cell temperature reference. $\alpha_{T}$ represents the temperature coefficient of the photocurrent. $I_{o R}, q$, and $k$ represent the dark current at $T_{c R}$, the electron charge, and the Boltzmann constant. $e_{g}$ and $n$ refer to the solar cell material bandgap energy and the ideality factor of diode.

\section{B. DC Link Capacitor and L Filter}

DC link capacitor is one of the most critical parts of the system as it provides several functions. It minimizes the voltage ripple across the PV terminals, which reduces the output power ripple during the transient states. It acts as a small energy storage unit for providing real power temporarily. Its size is determined as follows [11].

$$
C_{d c}=\frac{2 P_{\max }\left(\alpha_{\max }-1\right)}{f\left(V_{d c, h i g h}^{2}-V_{d c, l o w}^{2}\right)}
$$

$P_{\max }$ represents the maximum PV output power. $f$ and $V_{d c}$ refer to the frequency and DC-link voltage. $\alpha_{\max }$ indicates the ac mains cycle that the DC-side voltage will remain inside its hysteresis band, with $V_{d c \text {,high }}$ and $V_{d c, \text { low. }} \cdot \alpha_{\max }$ is given as:

$$
\alpha_{\text {max }}=\operatorname{Round}\left(1+\frac{V_{d c, \text { high }}^{2}-V_{d c, \text { low }}^{2}}{V_{d c}^{2}-V_{d c, \text { high }}^{2}}\right)
$$

For the model used in this paper, $V_{d c, h i g h}$ and $V_{d c \text {,low }}$ are $1.15 V_{D C}$ and $0.8 V_{D C}$, respectively, $P_{\max } \approx 5 \mathrm{~kW}, f=50 \mathrm{~Hz}$, $V_{D C}=500 \mathrm{~V}$.

The higher order harmonics caused by switching the inverter is limited by using an $L$ filter. The value of the $L$ filter of system at the grid side is obtained as follows:

$$
L_{f}=\Delta r\left(\frac{V_{p c c}}{2 \pi f I_{i n v}}\right)
$$

Where $\Delta r$ is the ripple of the current in ac side which considered as $\% 10$.

\section{The Inverter Controller Model}

The DC-AC inverter performs the conversion of the photovoltaic system direct power to the AC power. The switch-mode inverter produces a sinusoidal AC output from a DC input through PWM [14]. The inverter is a Voltage Source Converter (VSC), in which the controller works in PFC mode or voltage regulation mode. During PFC mode, the PV exchanges reactive power $(\mathrm{Q})$ for the grid and injects its available active power $(\mathrm{P})$ into the grid. In contrast, in the voltage regulation mode, the PV only generates its available maximum real power. The different subsystems of the PV controller are explained as follows.

\section{1) MPPT Controller}

The current and voltage of the photovoltaic cell are related nonlinearly as shown in Fig. 3. At MPP the PV generates its maximum output power. To determine the location of the MPP, several calculation models or search algorithms are developed to keep the PV array performing at its MPP. 


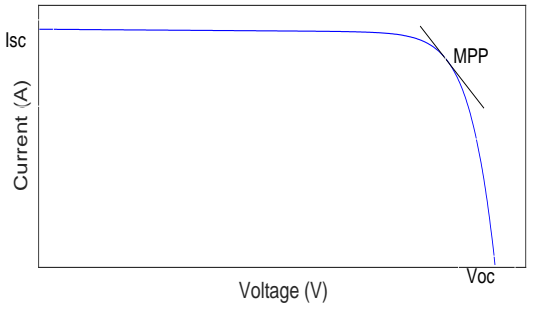

Fig. 3. I/V Characteristics of a PV Cell.

In this paper, the incremental conductance technique is used to find the MPP. Fig. 4 shows the flow chart in which the incremental algorithm detailed operation is described [12]. In this algorithm, the derivative of the output power of the PV array to its output voltage is calculated $(M=d P / d V)$. If $M$ is zero, the maximum PV output power is accomplished. If $M$ does not approach zero, the MPPT technique adjusts the PV voltage gradually until $M$ gets close to zero, then the photovoltaic panels move toward its highest output.

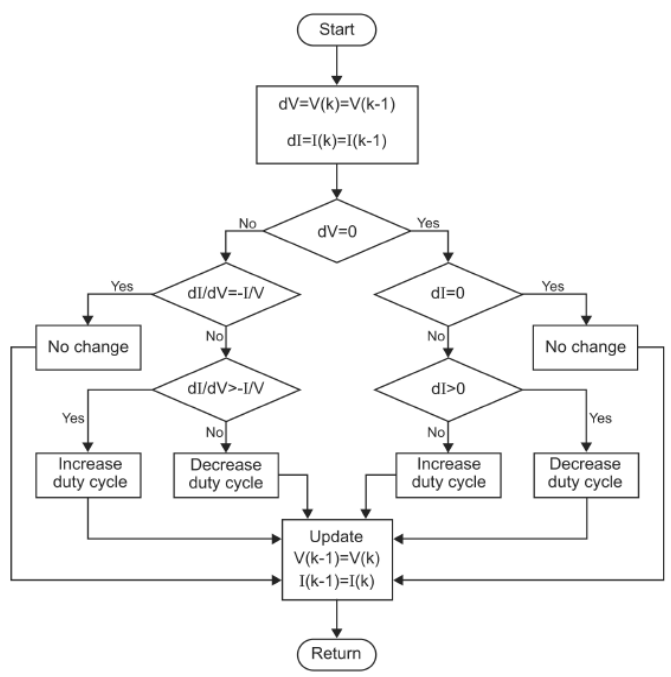

Fig. 4. Flow chart of the incremental conductance MPPT controller [12].

\section{2) DC Bus Voltage Control}

Fig. 5 presents the DC bus voltage controller. A compensator creates the reference active current, $I_{d r e f}$, then the voltage at the DC side is controlled to reach its optimum amount. The DC Bus voltage controller parameters are given in Table 1 .

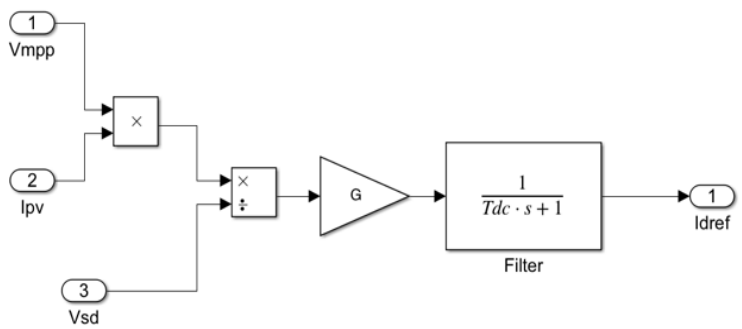

Fig. 5. DC Bus voltage controller.

\section{3) Power factor correction unit}

Power factor correction is presented in Fig. 6. is generated based on, $I_{L d}$ and $I_{L q} . I_{L d}$ and $I_{L q}$ refer to direct and quadrature axis current parts consumed by load. $I_{\text {Lqnew }}$ refers to load reactive component that needs to be drawn by the load from the grid.

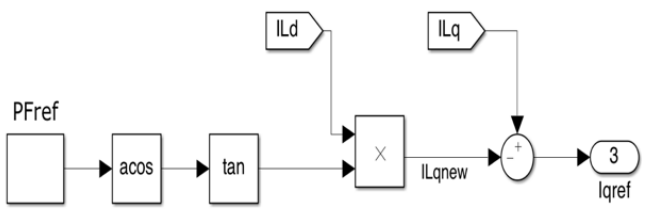

Fig. 6. Power factor correction unit.

\section{4) Current Controller}

The current controller unit plays an essential role in the PV controller. It has two controllers that independently control the VSC active and reactive currents $\left(I_{d}, I_{q}\right)$ to generate the VSC active and reactive voltages $\left(V_{s d}, V_{s q}\right) . I_{d}$ and $I_{q}$, are measured and injected into the associated controller. Those signals then are compared to $I_{\text {dref }}$ and $I_{\text {qref }}$ as reference values Then PI controllers receive error signals and generate active and reactive output voltage signals. The generated voltage signals are added to respective active and reactive grid voltages $\left(V_{s d}, V_{s q}\right)$ and coupling elements to generate inverter terminal voltages $\left(V_{t d}, V_{t q}\right)$. The current controller, shown in Fig. 7.

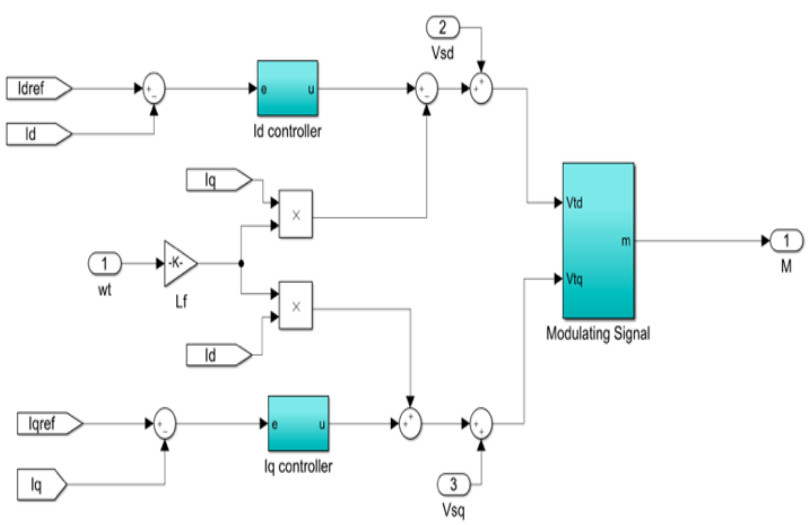

Fig. 7. Current controller

To generate the corresponding components of the modulating signals $\left(M_{d}, M_{q}\right)$ these VSC terminal voltages are divided by $\mathrm{V}_{\mathrm{dc}} / 2$ [13]. Modulation signals are then transformed into the sinusoidal modulating signal using $d-q$ to abc conversion to generate pulses to switch the inverter. The controller parameters such as $K_{p d}, K_{p q}, K_{i d}$, and $K_{i q}$ are given in Table 1.

TABLE 1 SYSTEM PARAMETERS

\begin{tabular}{cc}
\hline \multicolumn{2}{c}{ TABLE 1 SYSTEM PARAMETERS } \\
\hline System Parameters & Obtained \\
\hline PC link capacitor & $5 \mathrm{KW}$ \\
L filter & $6.5 \mathrm{mF}$ \\
rms voltage & $3.6 \mathrm{mH}$ \\
frequency & $230 \mathrm{~V}$ \\
$K_{p d}, K_{p q}$ & $50 \mathrm{~Hz}$ \\
$K_{i d}, K_{i q}$ & 250,1200 \\
$G, T_{d c}$ & $0.001,0.9$ \\
\hline
\end{tabular}

\section{Simulation ReSUlts}

The implementation of suggested control strategy has been done in the MATLAB/Simulink (R2020a) platform. The system's P, Q, voltage, and current are evaluated through the proposed control technique by considering 
different solar irradiance. The grid-connected PV system simulation is described in Fig. 8.

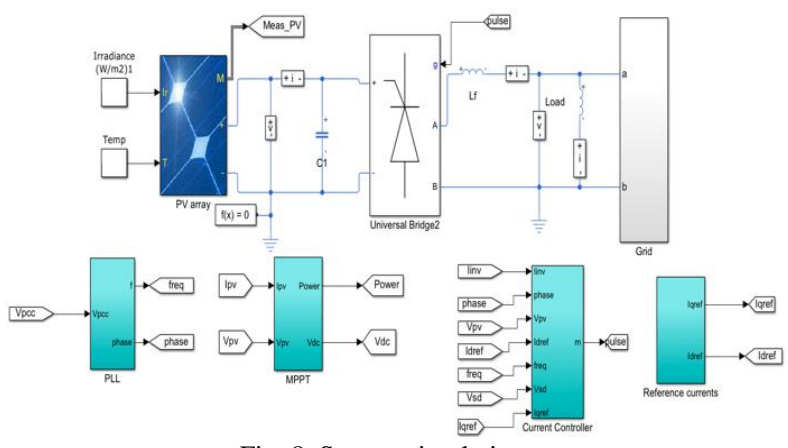

Fig. 8. System simulation.

The operation of controller is evaluated for $0-0.2 \mathrm{~s}$ to analyze its performance. Solar radiation levels are changed at $\mathrm{t}=0.12 \mathrm{~s}$ and $0.16 \mathrm{~s}$ to evaluate the results of variation of solar irradiance. The PF correction mode is evaluated during the time $0.035 \mathrm{~s}-0.1 \mathrm{~s}$. At $\mathrm{t}=0.05 \mathrm{~s}$, the PV controller operates in power factor correction mode, which causes the source's $\mathrm{PF}$ to be one, and PV generates all of the required load reactive power $\left(\mathrm{Q}_{\mathrm{L}}\right)$. The variation in solar irradiance is tested during the time of $0.1 \leq \mathrm{t} \leq 0.2$. At $\mathrm{t}=0.12 \mathrm{~s}$ and $0.16 \mathrm{~s}$, the PV generation is changed due to variation in solar irradiance.

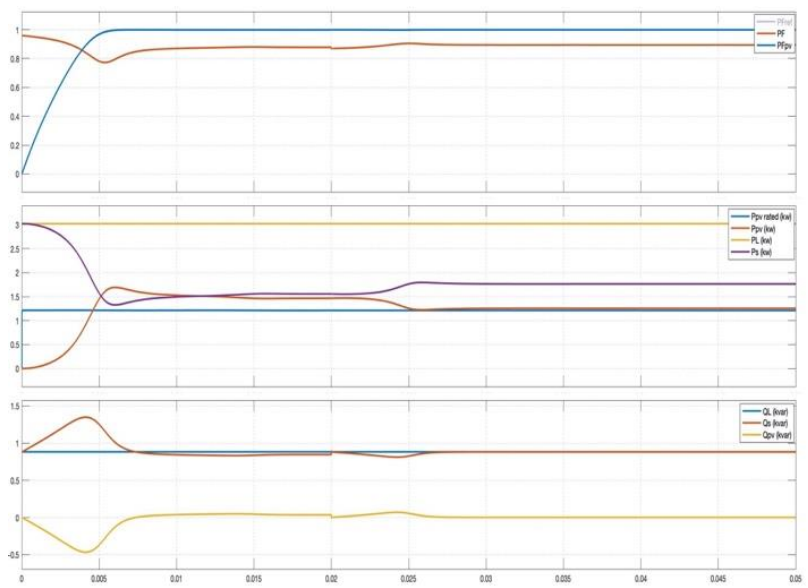

(a)

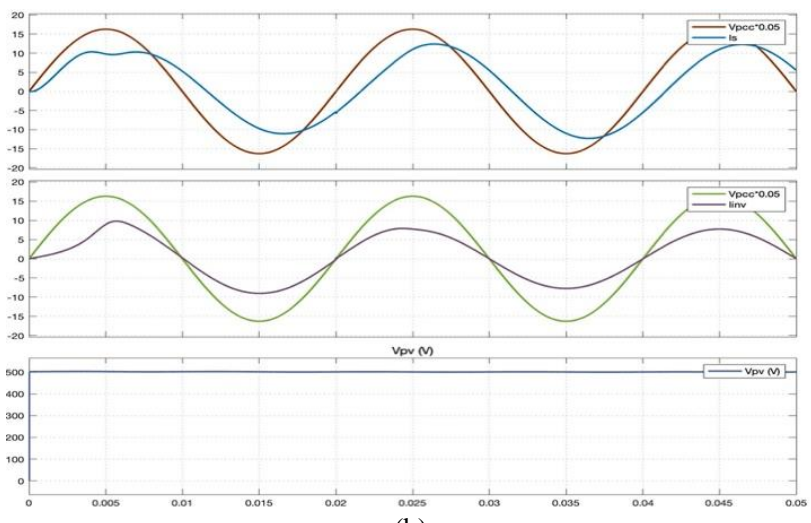

(b)

Fig. 9. (a) Voltage at PCC and DC side- Inverter and Source current. (b) P and $\mathrm{Q}$ of load, inverter, and source.

As Fig. 9 shows, the load active $\left(\mathrm{P}_{\mathrm{L}}\right)$ and $\mathrm{Q}_{\mathrm{L}}$ are 3.021 $\mathrm{KW}$ and 0.89 kvar, respectively, met by both $\mathrm{PV}$ and grid. The grid voltage is $325 \mathrm{~V}$, the maximum current, real power
$\left(\mathrm{P}_{\mathrm{S}}\right)$, reactive power $\left(\mathrm{Q}_{\mathrm{S}}\right)$, and $\mathrm{PF}$ of the source are $12.36 \mathrm{~A}$, $1.77 \mathrm{KW}, 0.89 \mathrm{kvar}$, and 0.889 , respectively. At the same time, these parameters for inverter output are $7.64 \mathrm{~A}, 1.256$ $\mathrm{KW}, 0$ kvar, and 1. In this simulation time, the PV is working in its unity power factor and generates its maximum available active power capacity in specified solar irradiance and is not injecting any reactive power to the grid.

Fig. 10 demonstrates the PV, load, and source parameters. At $0.05 \mathrm{~s}$, the controller starts to operate in PFC mode. When the transient period died out, the PPV is $1.248 \mathrm{~kW}$, and QPV is $0.89 \mathrm{kvar}$. Therefore, the controller entirely compensates for the QL requirement. Due to the slow DC voltage response, the active power response is slow compared to the reactive power response during the transient period.

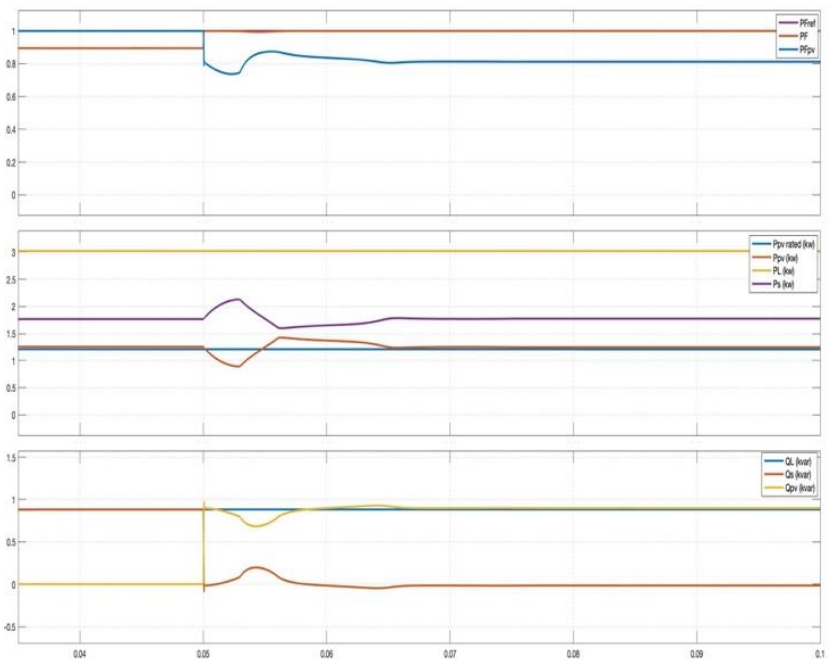

(a)

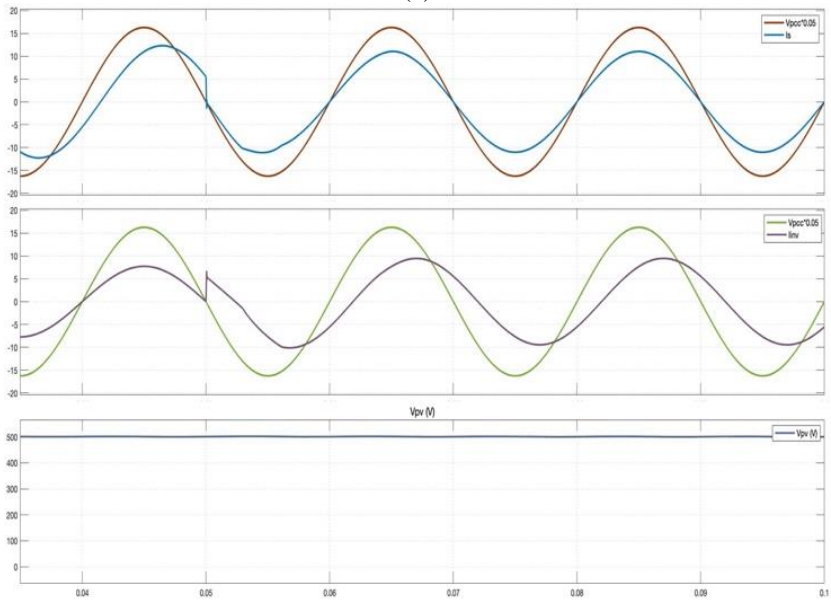

(b)

Figure 10. (a) Voltage at PCC and DC side- Inverter and Source current. (b) $\mathrm{P}$ and $\mathrm{Q}$ of load, inverter, and source.

Fig. 11 illustrates the evaluation of the proposed controller by changing solar irradiance. As shown in Fig. 11, not only is the power generated by PV follows the rated power, but the power factor correction is also met. 


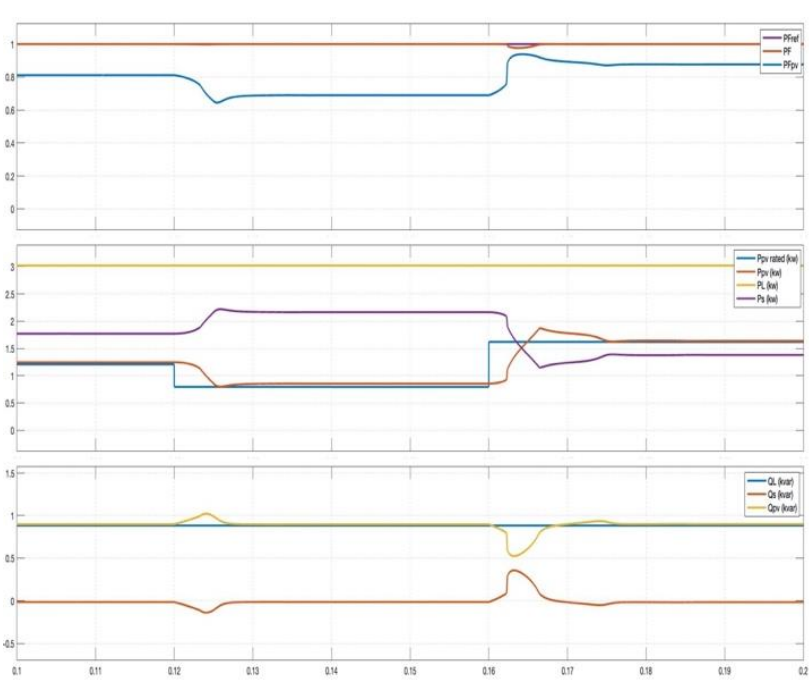

(a)

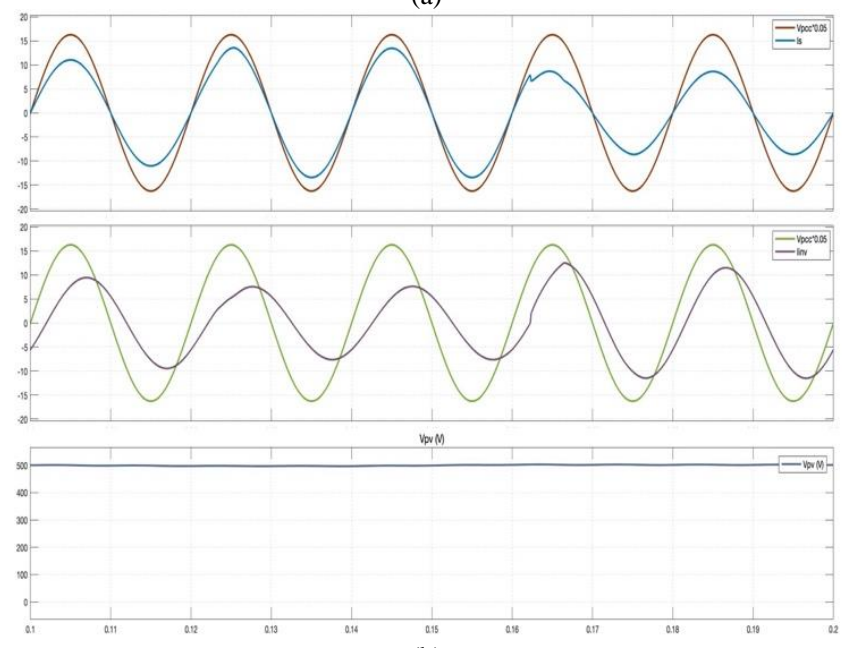

(b)

Figure 11. (a) Voltage at PCC and DC side- Inverter and Source current. (b) $\mathrm{P}$ and $\mathrm{Q}$ of load, inverter, and source.

\section{CONCLUSION}

In this paper, a proposed control design of a grid-tied single-phase PV inverter system for power factor correction is presented. Employing MPPT the PV array maximum available power is injected into the grid. According to the simulation results, $\mathrm{P}$ and $\mathrm{Q}$ can be adjusted properly utilizing the suggested control strategy. The proposed control technique function is carried out for different radiation levels. The proposed controller responses to the different variation fast and is quietly stable when the transient period died out. It responds to the commands of PFC in less than $1 \mathrm{~ms}$. The results show that the controller can perform reactive power compensation and maintain the constant voltage at the grid satisfying standard for grid interconnection. This control strategy is appropriate for providing the grid with reactive power, therefore, can help customers avoid usage penalties by generating active power. They also can generate profits from selling reactive power to the grid since the PV system can operate throughout the day for 24 hours.

\section{ACKNOWLEDGMENT}

The authors would like to thank the School of Graduate Studies, Faculty of Engineering and Applied Science, Memorial University and Pooya Pajouhan Nirouye Golpa Company.

\section{REFERENCES}

[1] B. K. Bose, "Global Warming: Energy, Environmental Pollution, and the Impact of Power Electronics", IEEE Industrial Electronics Magazine, vol. 4, no. 1, pp. 6-17, March 2010.

[2] H. Düz, " Storing solar energy inside compressed air through a heat machine mechanism", Gazi University Journal of Science, 29(2), 245$251,2016$.

[3] A. Scognamiglio, G. Adinolfi, G. Graditi and E. Saretta, "Photovoltaics in Net Zero Energy Buildings and Clusters: Enabling the Smart City Operation", Energy Procedia, vol. 61, pp. 1171-1174, 2014.

[4] X. Li, H. Wen, L. Jiang, Y. Hu and C. Zhao, "An Improved Beta Method with Autoscaling Factor for Photovoltaic System", IEEE Transactions on Industry Applications, vol. 52, no. 5, pp. 4281-4291, 2016.

[5] C. Ramulu, P. Sanjeevikumar, R. Karampuri, S. Jain, A. Ertas and V. Fedak, "A solar PV water pumping solution using a three-level cascaded inverter connected induction motor drive", Engineering Science and Technology, an International Journal, vol. 19, no. 4, pp 1731-1741, 2016.

[6] A. Cagnano, E. De Tuglie, M. Liserre and R. A. Mastromauro, "Online Optimal Reactive Power Control Strategy of PV Inverters," in IEEE Transactions on Industrial Electronics, vol. 58, no. 10, pp. 4549-4558, October 2011

[7] S. Balathandayuthapani, C. S. Edrington, S. D. Henry and J. Cao, "Analysis and Control of a Photovoltaic System: Application to a High-Penetration Case Study", IEEE Systems Journal, vol. 6, no. 2, pp. 213-219, June 2012.

[8] S. Gonzalez, J. Neely and M. Ropp, "Effect of non-unity power factor operation in photovoltaic inverters employing grid support functions," IEEE 40th Photovoltaic Specialist Conference (PVSC), Denver, CO, pp. 1498-1503, 2014.

[9] L. Wu, Z. Zhao, and J. Liu, "Intelligent controller for photovoltaic lighting systems", JOURNAL-TSINGHUA UNIVERSITY, 43(9), pp.1195-1198, 2003.

[10] W. Anthony, "Modeling and Analysis of a Photovoltaic System with a Distributed Energy Storage System," San Luis Obispo, M.Sc. Thesis, 2012.

[11] Y. Chen, C. Chang and H. Wu, "DC-link capacitor selections for the single-phase grid-connected PV system", International Conference on Power Electronics and Drive Systems (PEDS), Taipei, pp. 7277,2009.

[12] R.Faranda and S. Leva, "Energy Comparison of MPPT Techniques for PV Systems", WSEAS Transactions on Power Systems, Vol. 3, No. 6, pp. 446-455, 2008.

[13] V. Sineglazov and V. Kopanev, " Simulation Modeling of Solar Plants with Photoelectric Converters in the Mode of Selection in Maximum Power Point in Matlab/Simulink", Electronics and Control Systems, vol. 1, no. 51, pp. 134-139, 2017.

[14] A.Yazdani and R. Iravani, "Voltage-Sourced Converters: Modeling, Control, and Applications" Hoboken, NJ: Wiley, 2010. 